\title{
Marketing the Library and It Services with the Use of Social Media: An Overview
}

\author{
Okolo, Efe Stanley (CLN) \\ Collection Development Librarian: Rode Cecil Ibru Library \\ Michael and Cecilia Ibru University, Agbarha-Otor, Delta State
}

\begin{abstract}
This study explored how social media can be used to market library and it services for better patronage in the course of this the concept social media was defined in the following format Social: this term is referred to the process where there is an interaction of the individuals or group of people as it relate to the welfare of human beings as members of a given society.

Media: As the term implies, it is regarded as a platform of communication amongst members of a society and it comprises the following: Newspaper, radio etc therefore, Social Media can be defined as an instrument of interaction or communication between individuals or group of people. It is a tool that is based on the internet which is majorly used for communication, interaction, sharing and discussion of information amongst human beings. The study explained among others how library can use social media in marketing it resources,benefits for using social media in maketing libraries and it services, challenges in using social media for marketing the library and it services, the study was concluded on the platform that technology is a welcome development that must be used by libraries and librarians in order to attract the attention of patrons and with a recommendations for the various challenges that tend to prevent the better usage of the technology.
\end{abstract}

Keywords: Social, Media, Social Media, Social Media Marketing challenges.

DOI: $10.7176 / \mathrm{IKM} / 10-2-04$

Publication date: February $29^{\text {th }} 2020$

\section{Introduction}

In this our present dispensation and generation, social media has become a thing that almost every individuals old and young are engage in. they embrace it due to the fact that it serves as a means of interaction and communication. The world you see today has become a global village due to the coming of the internet where every other tool are hinged or connected to.

The library is a store house of information and gone are the days whereby the library will be left in just a particular place where whoever wants to make use of the resources contained in it must have to visit the library in person. The era we are in, is the computer age where information is seen as paramount due to the fact that it rules the world and anyone that has it in his or her possession is in power, as a result of this the library is regarded as the life wire and the brain house of any institution where it is established purposely because of the information it possesses and this information cannot be left lying fallow, it must be made accessible and available to those who seriously need them. To this end, the library and it services needs to be marketed or publicized beyond the four walls of the library so as to increase patronage and be relevant to the community it serves. According to Olajide, Otunla, and Omotayo (2017) posited that Social Media's presence is almost everywhere and the vision of the library within the last few years has been that library services should go to users not necessarily that users should come physically to the library. On the other hand, Taylor and Francis (2014) noted in their study that the upcoming wave of library patrons se students, colleagues and staff - will be from this generation who are technologically sophisticated, well connected on the social web, entrepreneurial and oftentimes impatient.

\section{The Concept Social Media}

For a better definition of this concept, the researcher is going to break the terms down bit by bit.

Social: this term is referred to the process where there is an interaction of the individuals or group of people as it relate to the welfare of human beings as members of a given society.

Media: As the term implies, it is regarded as a platform of communication amongst members of a society and it comprises the following: Newspaper, radio etc therefore, Social Media can be defined as an instrument of interaction or communication between individuals or group of people. It is a tool that is based on the internet which is majorly used for communication, interaction, sharing and discussion of information amongst human beings.

Social Media has been defined in several ways by different scholars. Okolo and Eserada (2019) posited that it is a channel that gives room for interaction or relationship between individuals, two or more people using computer systems such as phones, laptops or desktops with the aid of Internet connection services. In this same vein, Mislove (2009) defined social media as a system where (a) users are first class entities with semi-public profile (b) users can create explicitly links to other users or items and (c) users can navigate the social network 
by browsing the links and profile of other users. In addition to this, Boyd and Ellison (2007) also asserted that "social networking media is a web based service that allow individual to (1) construct a public or semi-public profile within a bounded system (2) articulate a list of other users with whom they share a connection and (3) view and traverse their list of connection and those made by others within the system." The growth in this social networking media such as Myspace, Facebook, Youtube, Fickr etc became so popular as a result of the increase in their usage. A social networking media is a huge leap in technological evolution in the world of Internet. The social networking media began to grow and also expanded. That was why Ahmed and Tehmina (2011) opined that the evolution of the social networking media started with Classmates.com which was founded in 1995. Oxford Dictionary (2013) defines Social Media as "websites and applications that enable users to create and share content or to participate in Social Networking". According to Bradley (2012) the term Social Media refers to "the use of web-based and mobile technologies to turn communication into an interactive dialogue". Kaplan \& Haenlein (2010) described Social Media as "a group of Internet-based applications that build on the ideological and technological foundations of Web 2.0, and that allow the creation and exchange of User Generated Content”.

How Social Media can be used in Marketing the Library and it Services.

Marketing refers to activities undertaken by a company, individuals engage in to promote the buying or selling of one's products or services. Social media is a crucial tool for marketing library resources and services. It does offer more than just the traditional ways of marketing library services. It allows users, staff to create, connect, converse, contribute, vote, react, and share information. Social media is helpful in accessing information needs of online users and helps libraries to get closer to the users. Different applications of social media are helpful for marketing library services among online community.

\section{Facebook:}

Most popular now because it is librarian- friendly, with many applications like JSTOR search, World Cat, and much more. Librarians can interact with users to know their information need. Libraries try to link some of these specialized library applications to Facebook.

MySpace:

In Academic institutions where the students are; libraries can take advantage of this site to post calendar, custom catalog search tools, and blog features to improve their presence.

Blogs:

Here, librarians can periodically post messages; share information on a particular subject or issue, and allow users to contribute to content. They can write articles, news on topical issues and expect an instant reaction from their users.

Wikis:

This is a free online encyclopedia that gives a background knowledge and definition of concepts. It offers a platform for users to access, edit and contribute to content. This is a collaborative web page for developing web content.

\section{LinkedIn:}

Librarians can get patrons connected with specialists in their particular field of interest via LinkedIn. Librarians can use this platform to render specialized services such as Strategic Dissemination of Information (SDI).

Twitter:

This is a micro blogging application; libraries can keep staff and patrons updated on daily activities, like frequently updated collections. Users can utilize this platform to type in short messages or status update. Librarians can use this platform to give users firsthand information on the on-going national elections. Users can send Instant Messages (IM) on complaints or ask questions on a particular issue and get a feedback on the spot using

\section{WhatsApp}

Librarians can send instant messages to users and get instant responses. Urgent information that requires Library users attentions can be communicated to users, even documents and materials can be send to users at any time and even outside the Library working hours.

In a study conducted by Khan and Bhatti (2012) the following points were also stated as the ways social media can be used to market the library and it services:

1. With the help of Facebook, libraries can advertise, showcase their different upcoming events, new delivered information resources.

2. Libraries can also market their different programs conferences workshops by uploading their videos on the YouTube.

3. They can also share and upload the pictures of different library events and services by using Flickr.

4. Libraries can use Facebook to share the information about their new arrivals and editions of books. 
5. RSS and Blogs can be used to market library services among distance learner. With the help of RSS, libraries can republish and syndicate the contents on the Web. Libraries can promote services, collection, events and resources by using social media.

6. Twitter and IM (Instant Messaging) can be used by the libraries to market library reference/research services.

7. Libraries can use Blogs to keep their users current with developments in the field of librarianship.

8. Professional Networking sites, i.e., LinkedIn can be used by the libraries to create professional connections and to market library services among other professionals working in different libraries of the world and can also solicit their ideas and professional experiences.

9. Social media in libraries can help in spreading news about the events in other libraries.

10. Social media as a tool in libraries can to publicize new acquired information resources and service alerts.

Different applications of social media are useful for libraries for obtaining their patron's feedback and to ensure the maximum engagement of their users in the production of their products and services. Social media is a fine tool for marketing library services among new generation users and to creating user-centered libraries.

\section{Benefits for using social media in marketing the library and it services}

Social media usage has been of great benefits to several libraries that have accepted to adopt it as a means of running the day to day activities or operations. In a study conducted by Akporhonor and Olise (2015) posited that social media usage in the library is of great importance because it helps in building brand loyalty, saves time, enhances fast two-way communication, saves costs and increases revenue and increases library users.

\section{Challenges in using social media for marketing the library and it services}

There are challenges that deter librarians from using the social media to market the library and it services and as such it makes the librarians not to embrace the coming of this technology in aiding the activities and operations of the library. Given below are some of the challenges that librarians usually encounter as enumerated by Islam and Habiba (2015)

1. Too many social media tools to learn,

2. Website is difficult to understand and use

3. Available information is not authentic

4. People can post whatever they want

5. Lack of knowledge how to use it

6. Low interest of librarians in learning and utilizing social media

7. Inadequate training opportunities for library staff

8. Electricity failure

9. Slow speed of internet

10. Difficult to cope with the rapid growth of such websites

11. Lack of security and privacy

12. Lack of advanced IT skills

\section{Conclusion and Recommendation}

It is true that with the coming of Internet several other sophisticated technologies have been developed and embraced over the years, and these technologies are been used by individuals and organizations and for libraries in this present dispensation to keep up and be able to measure up there is every need that these technologies are employed in the running of the day to day activities and operations of the libraries.

Gone are the days whereby users are under obligation to visit your library physically before they can have access to information resources reason been that the coming of the internet and the world wide web has made room for the proliferation and exponential growth for information and communication technology that users can possess at their fingertips which enables them to get through to any information on the net and some of them tend to be irrelevant and cost them time in gathering them.

In order to get the attention of patrons to the library and also market its services, it's relevant at this junction that:

- Library staff should be trained and re-train to acquire the technical know-how of the various social media tools

- Website should be made simple for easy understanding and navigation

- Information post should be authentic and relevant so as to encourage users to the platform

- There should be constant provision of electricity

- The bandwidth of the internet should be increased. 


\section{REFERENCES}

Akporhonor B. A. \& Olise F. N.(2015) Librarians' Use of Social Media for Promoting Library and Information Resources and Services in University Libraries in South-South Nigeria. Information and Knowledge Management. 5(6) 1-9

Boyd, D. M. \& Ellison N. B. (2007). Social Network Sites: Definition, History, and Scholarship. Journal of Computer Mediated Communication 6(4) 1-4.

Islam M. M. and Habiba U (2015) Use of Social Media in Marketing of Library and Information Services in Bangladesh. Journal of Library \& Information Technology. 35(4) 299-303

Kaplan, A. M., \& Haenlein, M. (2010). Users of the world, unite! The challenges and opportunities of SocialMedia. Business horizons, 53(1), 59-68.

Khan, Shakeel Ahmad \& Bhatti, Rubina (2012). Application of social media in marketing of library and information services: A case study from Pakistan. Webology, 9(1)

Mislove, A.E (2009). Online Networks Measurements, Analysis and Application to Distributed Information system.UnpublishedMsc Thesis.Rice University, Houston, USA.

Okolo, S. E. and Eserada, R. E, (2019). " Adoption Of Social Networks Media For Reference Services In Academic Libraries" Library Philosophy and Practice (e-journal). 2950. Retrieved from https://digitalcommons. unl.edu/libphilprac/2950

Olajide, A. A. and Otunla A. O. (2017) How Libraries Are Using Social Media: Nigeria Perspective. International Journal of Digital Library Services. 7(3) 79-94

Oxford Dictionary (2013) Definition of social media in English. (Retrieved 21st November 2019] Available from World Wide Web: http://www.oxforddictionaries.com/definition/english/social-media

Taylor \& Francis. (2014). Use of Social Media by the library current practices and future opportunities: A White Paper From Taylor \& Francis. 